\title{
Erratum to: Endoscopic transnasal intraorbital surgery: our experience with 16 cases
}

\author{
Paolo Castelnuovo - Iacopo Dallan · Davide Locatelli • Paolo Battaglia • \\ Paolo Farneti · Peter Valentin Tomazic • Veronica Seccia • \\ Apostolos Karligkiotis · Ernesto Pasquini · Heinz Stammberger
}

Published online: 20 March 2012

(C) Springer-Verlag 2012

\section{Erratum to: Eur Arch Otorhinolaryngol}

\section{DOI 10.1007/s00405-011-1917-z}

The author would like to correct his misspelled name in the original version of the published article. The correct name should be "Apostolos Karligkiotis".

The online version of the original article can be found under doi:10.1007/s00405-011-1917-z.

P. Castelnuovo $\cdot$ I. Dallan · P. Battaglia $\cdot$ A. Karligkiotis

ENT Unit, Azienda Ospedaliero-Universitaria,

Ospedale di Circolo e Fondazione Macchi,

Varese, Italy

D. Locatelli

Neurosurgical Department, University of Pavia,

Pavia, Italy

P. Farneti · E. Pasquini

ENT Department, Bellaria Hospital, Bologna, Italy

P. V. Tomazic $\cdot$ H. Stammberger

ENT Department, University of Graz, Graz, Austria

V. Seccia $(\square)$

Department of Otorhinolaryngology, 1st ENT Unit,

Azienda Ospedaliero-Universitaria Pisana,

Via Paradisa 2, 56122 Pisa, Italy

e-mail: veronicaseccia@gmail.com 